\title{
Recent advances on diversity oriented heterocycle synthesis via multicomponent tandem reactions based on $\mathrm{A}^{3}$ coupling
}

\author{
Yunyun Liu*a,b \\ ${ }^{a}$ Key Laboratory of Functional Small Organic Molecule, Ministry of Education, \\ Jiangxi Normal University, Nanchang 330022, P. R. China \\ ${ }^{b}$ College of Chemistry and Chemical Engineering, Jiangxi Normal University, \\ Nanchang 330022, P. R. China \\ E-mail:chemliuyunyun@gmail.com
}

DOI: $\underline{\text { http://dx.doi.org/10.3998/ark.5550190.p008.183 }}$

\begin{abstract}
$\mathrm{A}^{3}$ coupling reactions are the reactions between aldehydes, amines and alkynes, which yield propargylamine derivatives under various catalyst conditions. By making use of the versatile reactivity of propargylamines, tandem reactions initiated by the functional group(s) in the in situ generated propargylamines constitute one of the most important applications of $\mathrm{A}^{3}$ couplings. These tandem reactions are especially useful for the synthesis of heterocyclic compounds. In this review, the progress on multicomponent tandem reactions based on $\mathrm{A}^{3}$ coupling is summarized.
\end{abstract}

Keywords: $\mathrm{A}^{3}$ Coupling, tandem, multicomponent reactions, heterocylic compounds

\section{Table of Contents}

1. Introduction

2. Heterocycle Synthesis via Tandem Multicomponent Reactions Based on $\mathrm{A}^{3}$ Coupling

2.1 Reactions based on functional amine participated tandem $\mathrm{A}^{3}$ coupling transformation

2.2 Reactions based on functional aldehyde participated tandem $\mathrm{A}^{3}$ coupling transformation

2.3 Reactions based on functional alkyne participated tandem $\mathrm{A}^{3}$ coupling transformation

2.4 Reactions of more than three components based on $\mathrm{A}^{3}$ coupling tandem transformation

3. Conclusions and Outlook

References

\section{Introduction}

The $\mathrm{A}^{3}$ coupling reactions are known as the three-component reactions of aldehydes, amines and alkynes yielding propargylamines as products. The earliest example of this kind of 
transformation can be dated back to 1953, when Guermont employed terminal alkynes, secondary amines and formaldehyde for the synthesis of propargylic amino ethers. ${ }^{1}$ During the past several decades, the group of $\mathrm{Li}$ has conducted seminar work in exploring these reactions and named these reactions as $\mathrm{A}^{3}$ coupling based on the three characteristic reactants involved in the reactions (Scheme 1). ${ }^{2-6}$

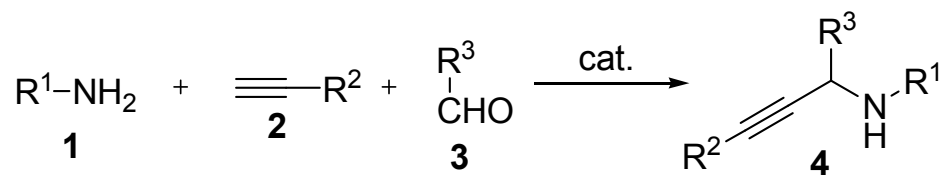

\section{Scheme 1}

Owing to the important and broad applications $\mathrm{A}^{3}$ coupling has exhibited, worldwide attention has been drawn to this research field. The advantages of $\mathrm{A}^{3}$ coupling reactions, such as excellent functional group tolerance and the broad utilities of propargylamine products in organic synthesis, account mainly for the prevalent interests afforded to these reactions. ${ }^{7-9}$ Among the numerous synthetic examples associated with $\mathrm{A}^{3}$ coupling chemistry, tandem reactions involving $\mathrm{A}^{3}$ coupling as key transformation has evolved as versatile tools for the synthesis of structurally diverse heterocyclic products. These syntheses were usually achieved via the transformations on the in situ generated propargylamines in the presence of a second functional group located in the propargylamine intermediates or provided by other additional component. These tandem reactions involved at least the formation of three new chemical bonds and shown widespread application in the synthesis of heterocyclic products. In this present review, we comprehensively summarized the progress on $\mathrm{A}^{3}$ coupling-based tandem reactions for heterocycle synthesis. The reactions were classified based on the location of second functional group that initiates the tandem annulation after $\mathrm{A}^{3}$ coupling.

\section{Heterocycle Synthesis via Tandem Multicomponent Reactions via $\mathbf{A}^{3}$ Coupling}

\subsection{Reactions based on functional amine participated tandem $\mathrm{A}^{\mathbf{3}}$ coupling transformation} Among the three reactants of $\mathrm{A}^{3}$ coupling reactions, amines possessed the most versatile structural variability and flexibility since they could participate in the reactions not only in the form of aromatic and aliphatic substrates, but also in the form of primary amine, secondary amine or even ammonia. Therefore, it was convenient to devise $\mathrm{A}^{3}$ coupling-based tandem reaction to access heterocyclic scaffolds by using the functional amines. In 2002 , Iqbal ${ }^{10}$ and coworkers reported the first $\mathrm{CuCl}$-catalyzed three-component reactions of aromatic amines, akynes and aldehydes for direct synthesis of quinolines. The reactions were performed in refluxing THF and provide quinolines 5 in 31-48 \% yield while propargylamine products 6 occurred as side or only products in some entries. During the reaction process forming $\mathbf{5}, \mathrm{A}^{3}$ coupling products $\mathbf{6}$ 
were the key intermediates, the tautomerization of $\mathbf{6}$ to intermediates 7 with copper catalysis led to transition state $\mathbf{8}$, and the nucleophilic carbon site in amines initiated the intramolecular annulation to provide the other key intermediates $\mathbf{9}$ which underwent aromatization to give products 5 (Scheme 2).

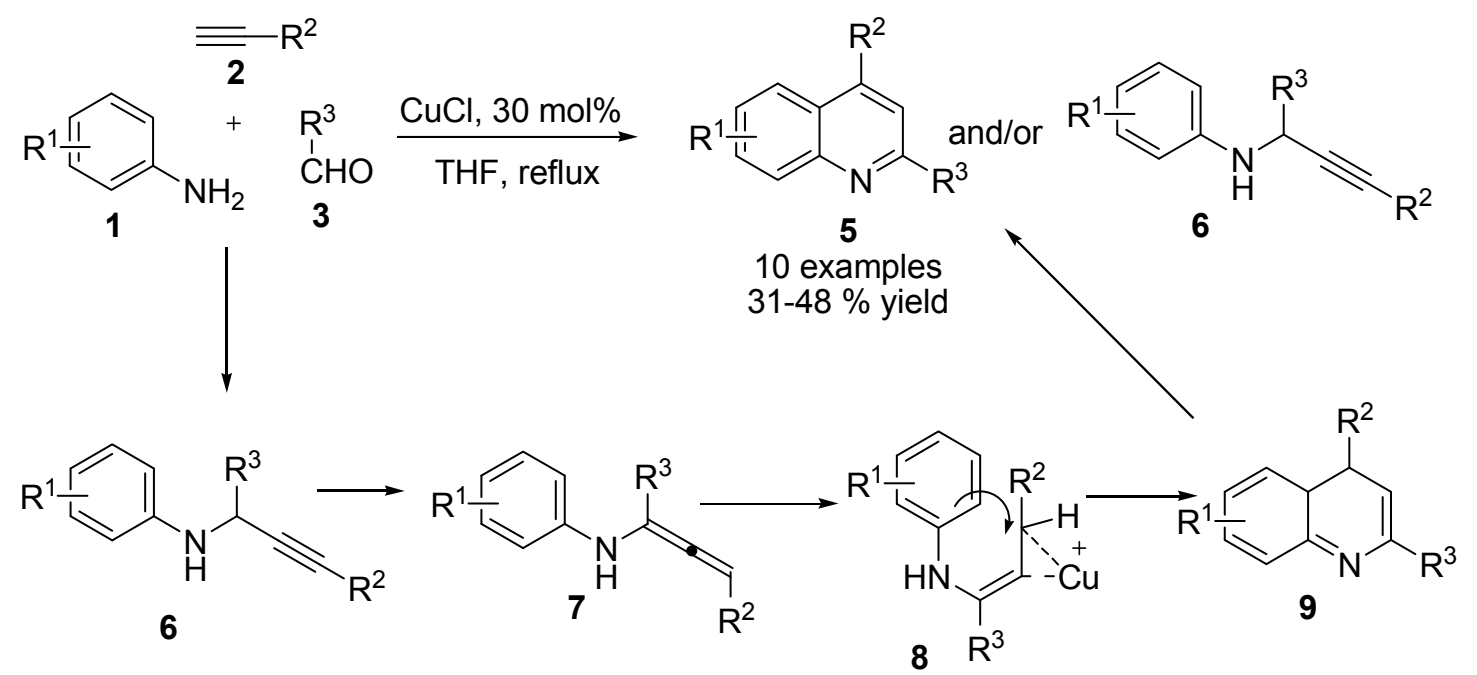

\section{Scheme 2}

Wang ${ }^{11}$ et al. employed $\mathrm{AuCl}_{3}$ and $\mathrm{CuBr}$ as mixed catalysts in methanol solvent to carry out the same multicomponent reactions, which remarkably enhanced the product yields (Scheme 3). Later on, $\mathrm{Tu}^{12}$ and coworkers developed a new atom economical protocol for quinolines synthesis wherein $\mathrm{FeCl}_{3}$ was used as catalyst, and the reactions were performed in toluene at 110 ${ }^{\circ} \mathrm{C}$ with moderate to excellent yield of products (Scheme 3). Similar results has also later been reported by Wang and coworkers. ${ }^{13}$ Recently, iron species $\mathrm{Fe}\left(\mathrm{CF}_{3} \mathrm{COO}\right)_{3}{ }^{14}$ and $\mathrm{Fe}(\mathrm{OTf})_{3}{ }^{15}$ were respectively reported as efficient catalysts for quinolines synthesis via the same multicomponent reactions. On other othe hand, Kumar ${ }^{16}$ and coworkers developed a rapid catalytic method for the reaction using $\mathrm{Yb}(\mathrm{OTf})_{3}$ catalyst in ionic liquid medium with the promotion of microwave, advantages of broad application scope as well as excellent product yield have been demonstrated (Scheme 3). Following this work, Wang $^{17}$ et al. devised recyclable Ytterbium catalyst $\mathrm{Yb}(\mathrm{Pfb})_{3}$ $(\mathrm{Pfb}=$ pentafluorobenzoates $)$ to enable the this transformation under solvent-free condition with good to excellent yields of quinolines. Mohammadpoor-Baltork ${ }^{18}$ et al. synthesized a series of similar quinolines using this three-component assembly employing $\mathrm{K}_{5} \mathrm{CoW}_{12} \mathrm{O}_{40} \cdot 3 \mathrm{H}_{2} \mathrm{O}$ as catalyst under microwave irradiation, products were obtained with generally excellent yields with solvent-free operation (Scheme 3). 


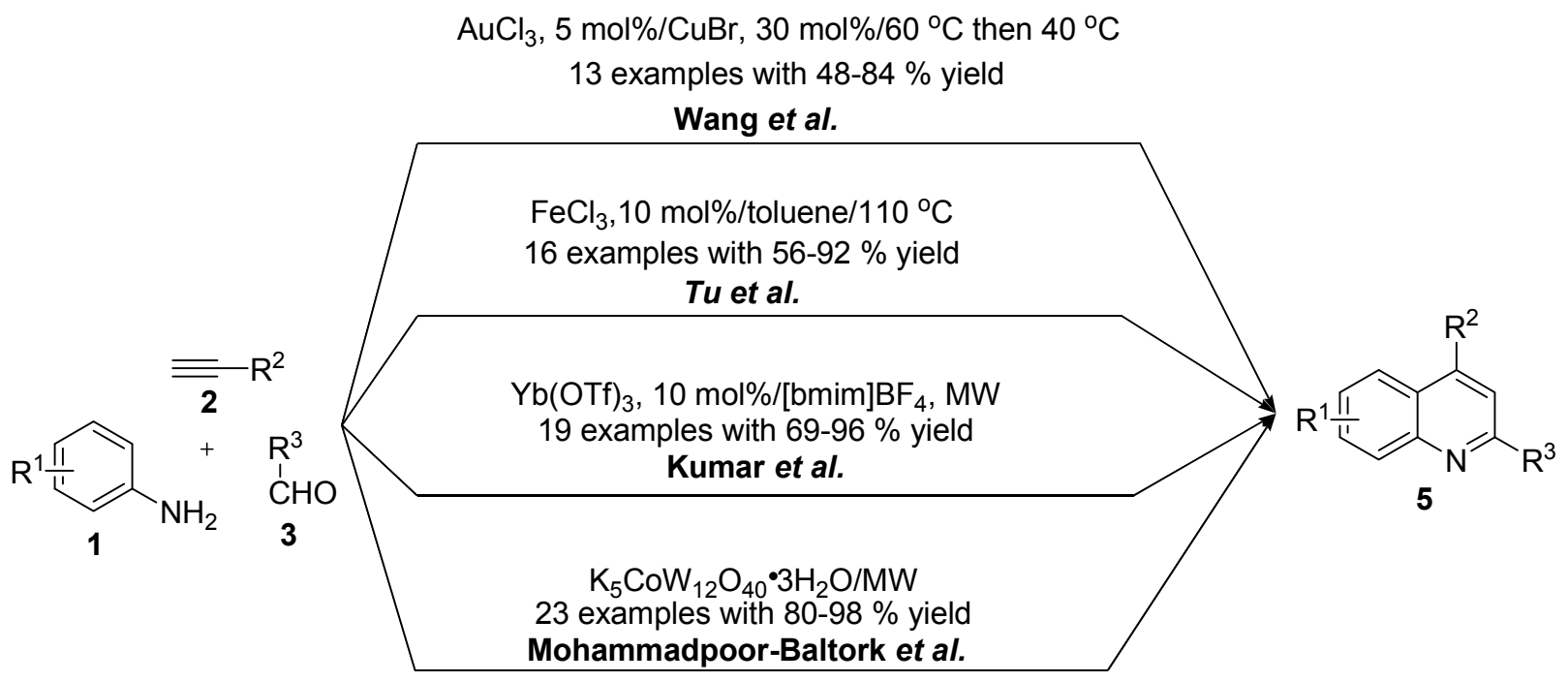

\section{Scheme 3}

Besides quinolines 5, many other heterocyclic products bearing quinoline backbone have been found readily accessible through the same kind of tandem reactions, for example, Nagarajan $^{19}$ and co-workers developed the three-component reactions of aminocarbazoles 11, adehydes and terminal alkynes for the synthesis of polycyclic scaffolds $\mathbf{1 2}$ with excellent application scope. The reactions were performed in ionic liquid $\left[\mathrm{Bmim}_{\mathrm{B}}\right] \mathrm{BF}_{4}$ at $100{ }^{\circ} \mathrm{C}$ in the presence of $\mathrm{Cul} / \mathrm{La}(\mathrm{OTf})_{3}$ co-catalysts (Scheme 4).
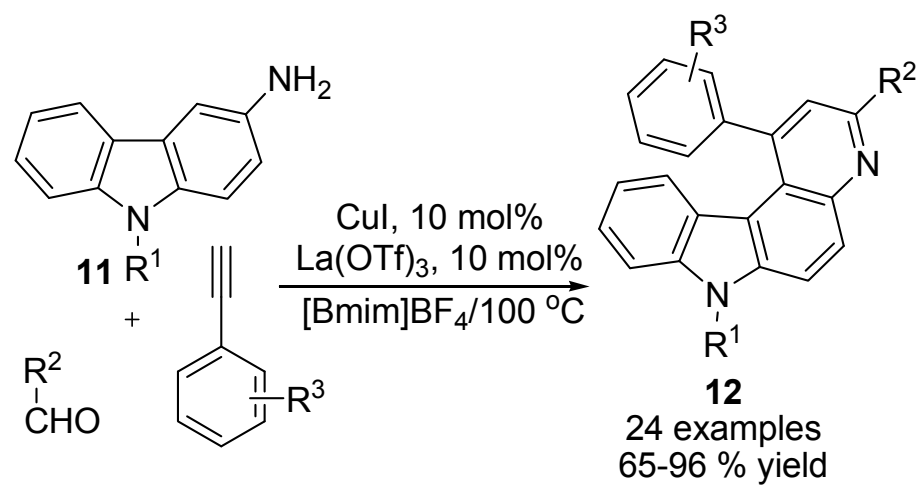

\section{Scheme 4}

On the other hand, $\mathrm{Zhang}^{20}$ et al. investigated similar three-component reactions using fluorine functionalized aldehydes $\mathbf{1 3}$, the reactions conditions of $\mathrm{CuCl}$ catalysis and microwave assistance enabled the synthesis of various fluorine containing quinoline derivatives $\mathbf{1 4}$. Based on the difference in reactions conditions, reactions could proceed to the stage of conventional $\mathrm{A}^{3}$ coupling products or products $\mathbf{1 4}$, the selectivity of the reactions were mainly determined by 
oxidative conditions, the air atmosphere mainly led to the production of quinoline products (Scheme 5).

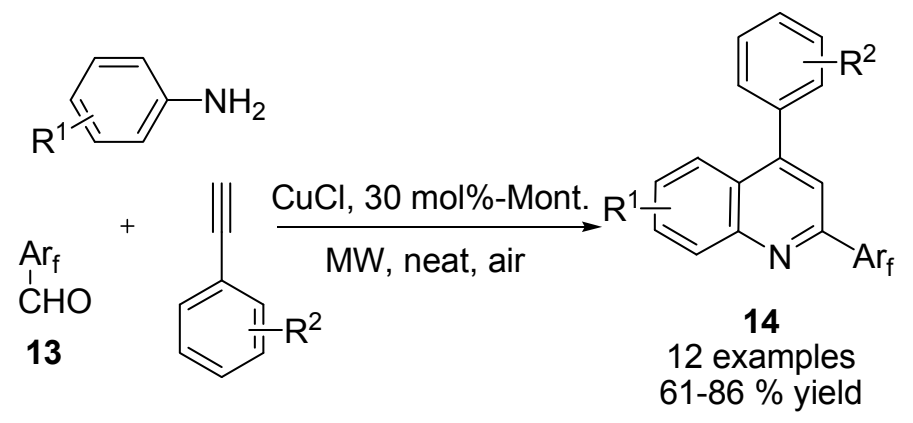

\section{Scheme 5}

As another frequently utilized $N$-nucleophiles, hydrazines could be used as alternatives of amines for three-component coupling reactions with aldehydes and terminal alkynes. After $\mathrm{A}^{3}$ coupling, tandem annulation/aromatization transformation could be initialized to provide pyrazole products. Pan and co-workers ${ }^{21}$ employed PTSA catalyst and achieved the threecomponent reactions of hydrazines 15, aldehyde and terminal alkynes for tandem synthesis of pyrazoles 16, the key intermediates $\mathbf{1 7}$ in the reactions were generated from the hydrazine-based $\mathrm{A}^{3}$ coupling (Scheme 6).

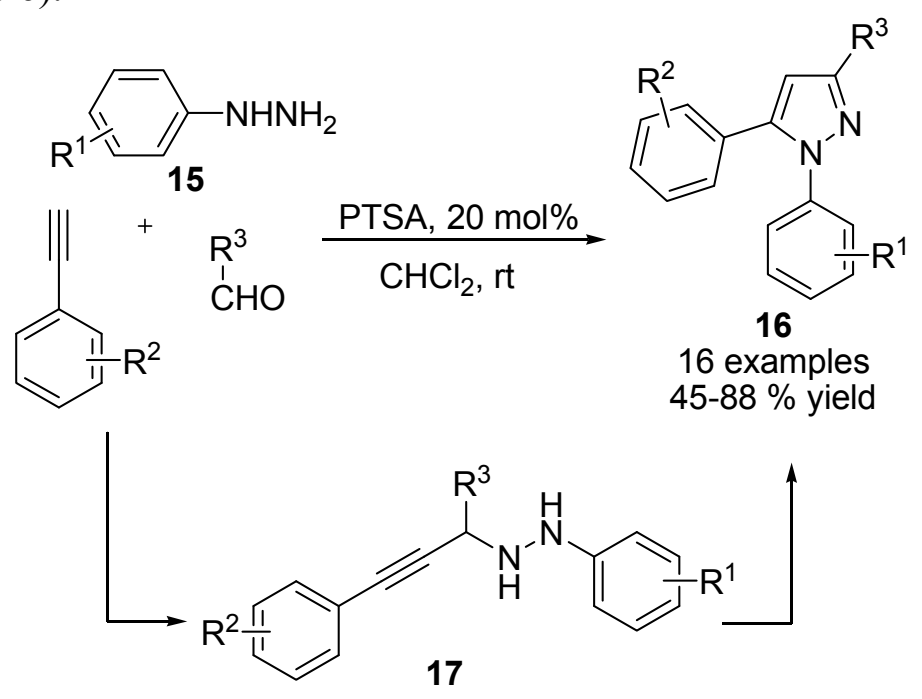

\section{Scheme 6}

Imidazo[1,2-a]pyridine is another useful heterocyclic backbone that can be easily constructed through functional amine initiated, $\mathrm{A}^{3}$ coupling-based tandem reactions. Gevorgyan $^{22}$ and co-workers employed 2-aminopyridine 18 as amine component for $\mathrm{A}^{3}$ coupling tandem reactions, and the coupled intermediates $\mathbf{2 0}$ have been directly transformed to 
imidazo[1,2-a]pyridines $\mathbf{1 9}$ as products through 5-exo-dig annulation in the presence of $\mathrm{CuCl} / \mathrm{Cu}(\mathrm{OTf})_{2}$ co-catalysts (Scheme 7).

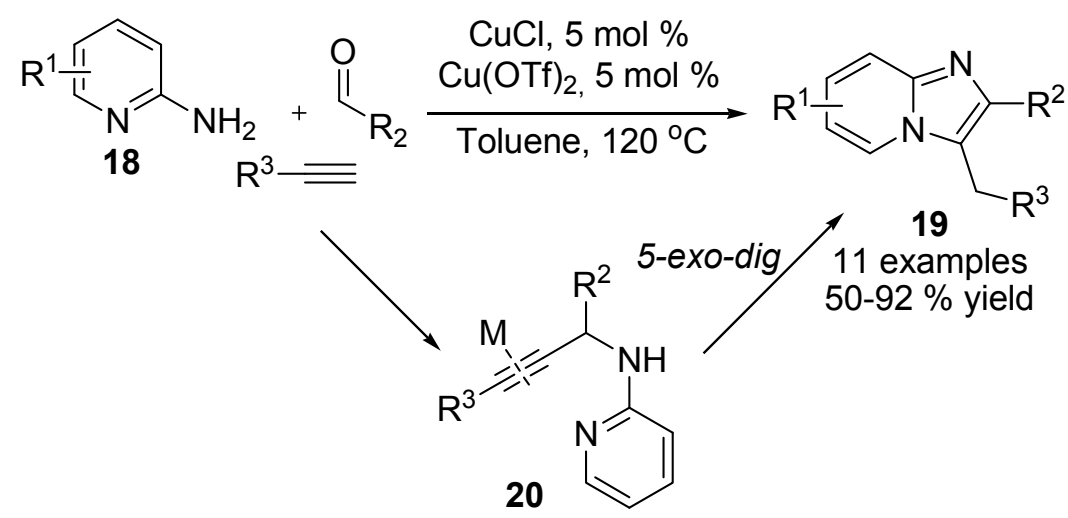<smiles>c1ccc(Cc2c(-c3ccccc3)nc3ccccn23)cc1</smiles>

$92 \%$<smiles>CCCCCN(Cc1ccccc1)c1c(OCc2ccccc2)nc2ccccn12</smiles>
$80 \%$<smiles>CCCCCc1c(-c2ccccc2)nc2ccccn12</smiles>

$44 \%$<smiles>O=COCc1c(-c2ccccc2)nc2ccccn12</smiles>

$90 \%$<smiles>CCCCCOc1nc2ccccn2c1Cc1ccccc1</smiles><smiles>c1ccc(Cc2c(-c3ccccc3)nc3ccccn23)cc1</smiles>
$50 \%$<smiles>CCCCOc1nc2ccccn2c1Cc1ccccc1</smiles>
$89 \%$<smiles>CCCCOc1nc2ccccn2c1C[O+]=O</smiles>

$86 \%$<smiles>CCCc1c(-c2ccccc2)nc2ccccn12</smiles>

$70 \%$

\section{Scheme 7}

Later on, various other different catalysis conditions have been developed to smoothly perform the same reactions. Ghosh et $a .^{23}$ employed $\mathrm{CuI}$ catalyst to carry out the threecomponent assembly in reflux toluene in the presence of $\mathrm{NaHSO}_{4} \cdot \mathrm{SiO}_{2}$ additive, and corresponding products were obtained with good to excellent yield (Equetion 1, Scheme 8), while Guchhait ${ }^{24}$ group devised an interesting protocol of D-glucose $/ \mathrm{CuSO}_{4} \cdot 5 \mathrm{H}_{2} \mathrm{O}$ catalysis to performed this three-component heterocycle synthesis wherein $\mathrm{Cu}(\mathrm{I})$ species has been generated in situ via reduction of partial $\mathrm{CuSO}_{4} \cdot 5 \mathrm{H}_{2} \mathrm{O}$ to serve as cocatalyst of $\mathrm{Cu}(\mathrm{II})$. The application 
scope of reactions in this work has been extended to other heteroaryl amines from 2aminopyridine (Equetion 2, Scheme 8).

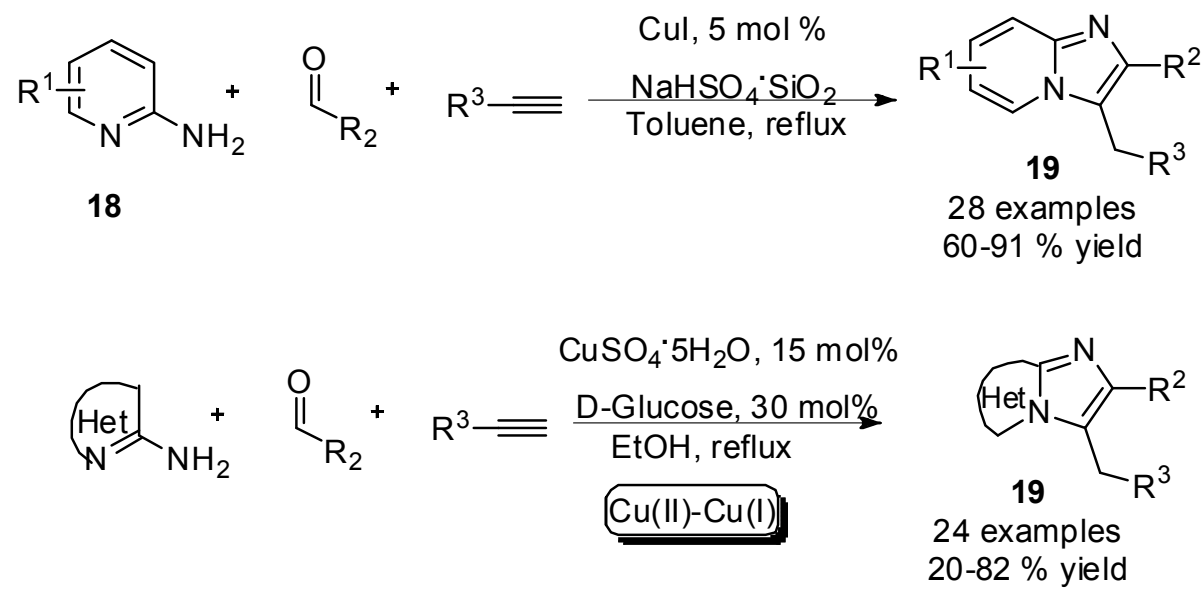

\section{Scheme 8}

\subsection{Reactions based on functional aldehyde participated tandem $\mathbf{A}^{3}$ coupling transformation}

As the electrophilic component in $\mathrm{A}^{3}$ coupling reaction, aldehyde has exhibited excellent tolerance to catalytic conditions and functional groups, meanwhile, aldehydes containing many other reaction functional groups were usually of easy access, employing functional aldehydes for the design of $\mathrm{A}^{3}$ coupling based tandem reactions for heterocycle synthesis is also important content in $\mathrm{A}^{3}$ coupling reactions. For example, $\mathrm{Liu}^{25}$ and co-workers achieved the threecomponent synthesis of indolizine 21 through the reactions of pyridinly-2-aldehydes, terminal alkynes and amines. The loading of $1 \mathrm{~mol} \% \mathrm{NaAuCl}_{4} \cdot 2 \mathrm{H}_{2} \mathrm{O}$ catalyst and $60{ }^{\circ} \mathrm{C}$ heating efficiently promoted the synthesis of different indolizines under solvent-free operation. The key transformation of the reaction was also $\mathrm{A}^{3}$ coupling of three components yielding corresponding propargylamine intermediates 22, and the insertion of Au catalyst to C-C triple bond on 22 initiated further tandem annulation to provide final products $\mathbf{2 1}$ with moderate to excellent yield (Scheme 9). 


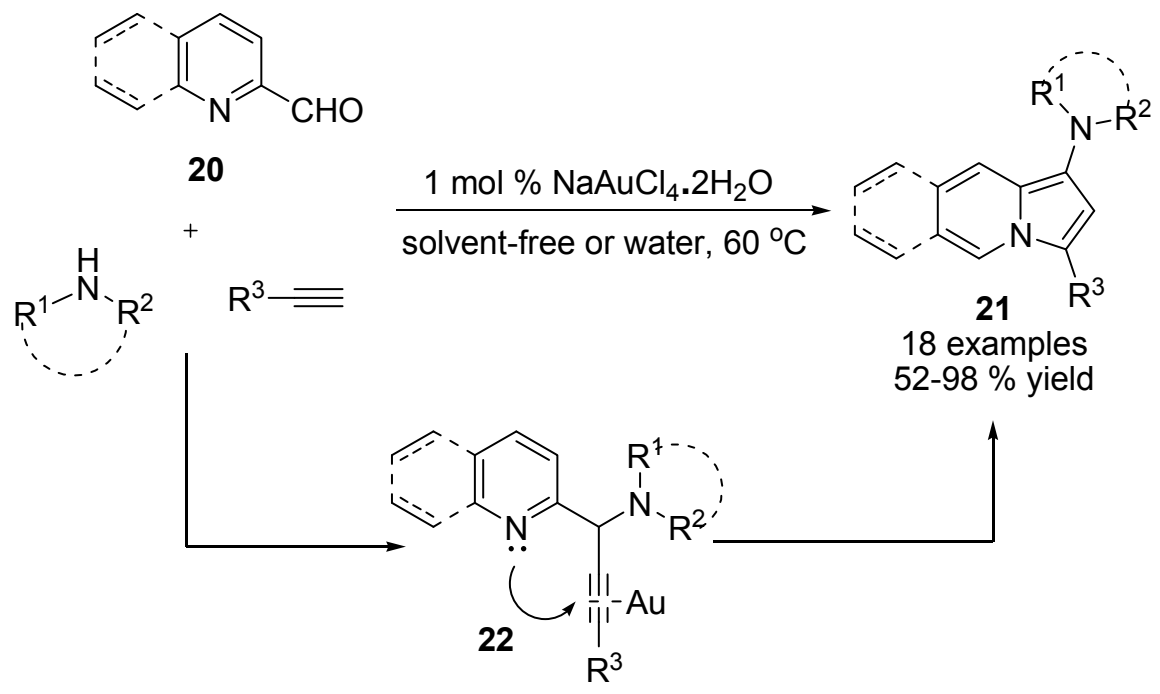

\section{Scheme 9}

Successful synthesis of indolizine derivatives via this kind of reactions triggered considerable research efforts in improving the reactions through a number of other catalytic methods. For example, the $\mathrm{AgBF}_{4} /$ toluene ${ }^{26}, \mathrm{Fe}(\mathrm{acac})_{3} / \mathrm{TBAOH}^{27}$ and $\mathrm{CuI} / \mathrm{PEG}^{28}$ system etc. have all been reported as good methods for this three-component synthesis (Scheme 10).

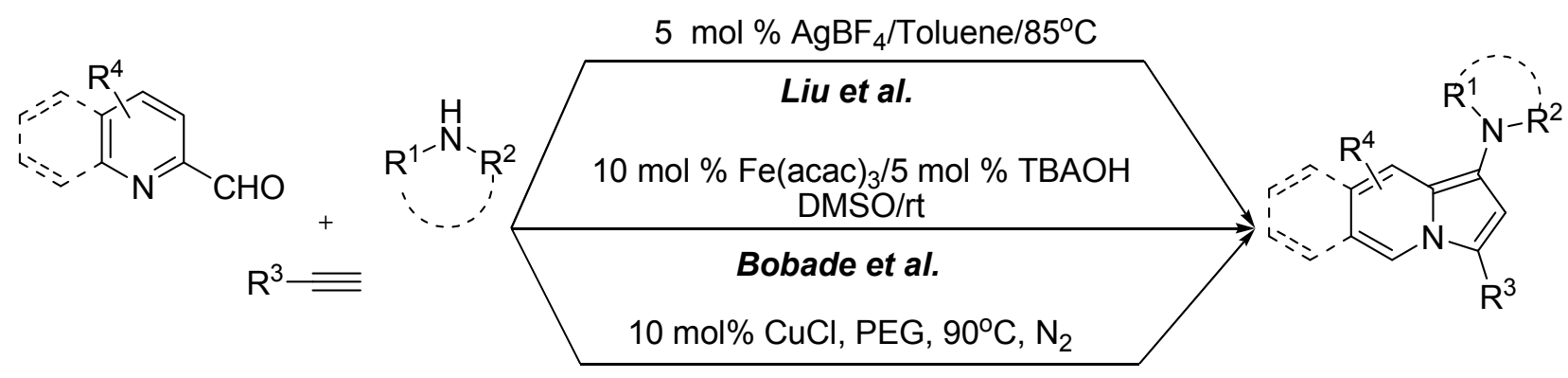

Ghosh et al.

\section{Scheme 10}

Batra $^{29}$ et al. utilized polycyclic compounds $\mathbf{2 3}$ which contain a pyridinyl-2-aldehyde fragment to incorporate amine and terminal alkynes for similar reaction, and a series of polycyclic scaffolds $\mathbf{2 4}$ have been synthesized with excellent application scope on substrates (Scheme 11). 


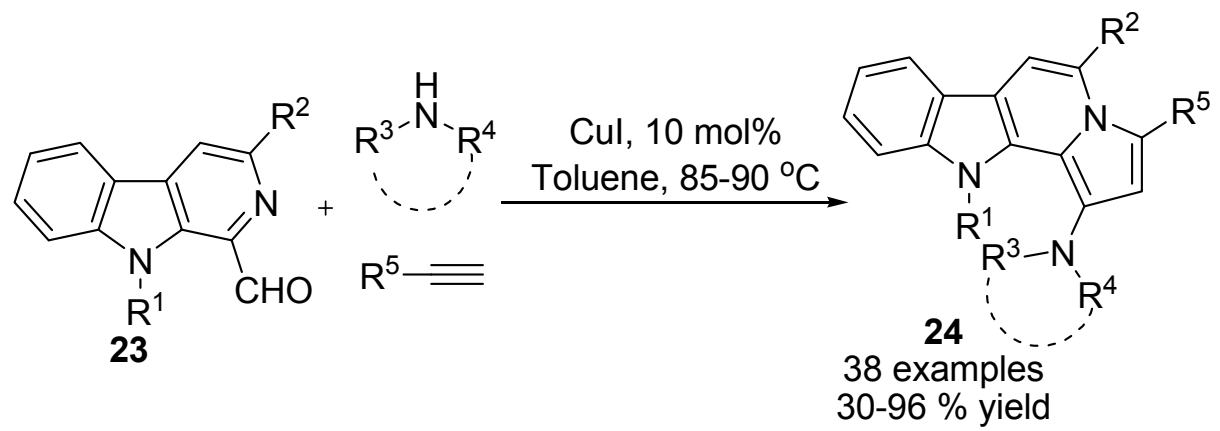

\section{Scheme 11}

Among the various available functional aromatic aldehydes, salicaldehyde is one of the most frequently utilized species in the synthesis of heterocyclic products. Reasonably, salicaldehyde was also useful building block in the synthesis of heterocyclic compounds via $\mathrm{A}^{3}$ coupling based tandem reactions. $\mathrm{Li}^{30}$ and co-workers reported $\mathrm{CuI}$ (some examples with $\mathrm{AgCl}$ )-catalyzed threecomponent synthesis of dihydrobenzofuran derivatives 27 by making use of salicaldehydes $\mathbf{2 5}$, terminal alkynes $\mathbf{2 6}$ and cyclic secondary amines as starting materials. $\mathrm{A}^{3}$ coupled products $\mathbf{2 8}$ were key intermediates in the reactions, and the hydroxyl or amino functional group has been found to be key factor determining the chemo-selectivity of the reaction since these functional groups were able to interact with $\mathrm{Au}$ catalyst via hydrogen bond and promote the activation of gold catalyst on $\mathrm{C}-\mathrm{C}$ triple bonds to trigger subsequent transformation, while alkynes containing no hydroxyl or amine group led to the formation of only tradition $\mathrm{A}^{3}$ coupling products (Scheme 12).

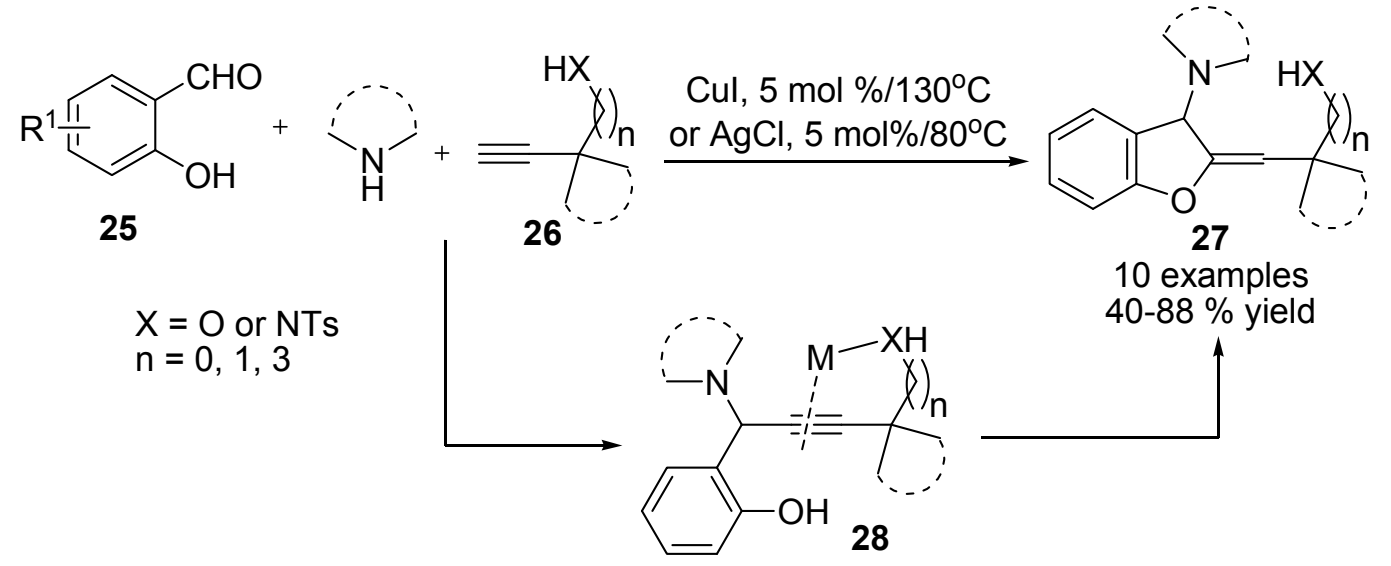

\section{Scheme 12}

Sakai $^{31}$ and co-workers discovered that trimethylsilyl substituted alkynes 29 in stead of terminal alkynes could proceed directly to benzofuran derivatives $\mathbf{3 0}$ via 5-exo-dig annulation, 
these reactions were performed in reflux $\mathrm{MeCN}$ using $\mathrm{Cu}(\mathrm{OTf})_{2}$ as catalyst and DMAP as additive (Scheme 13).

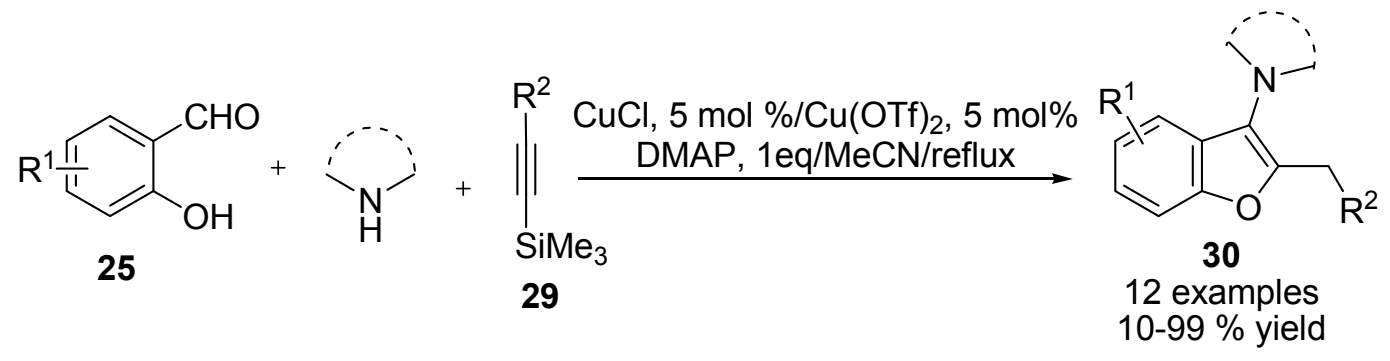

\section{Scheme 13}

Interestingly, $\mathrm{Li}^{32}$ and co-workers found that employing terminal alkynes containing no silyl group, salicaldehydes and secondary amines was also able to afford benzofurans $\mathbf{3 0}$ through three-component tandem reactions. Products were provided with generally good yields in the presence of $\mathrm{CuI}$ catalyst, and $\mathrm{K}_{2} \mathrm{CO}_{3}$ as well as $\mathrm{Bu}_{4} \mathrm{NBr}$ additives in toluene at $110{ }^{\circ} \mathrm{C}$ (Scheme 14).

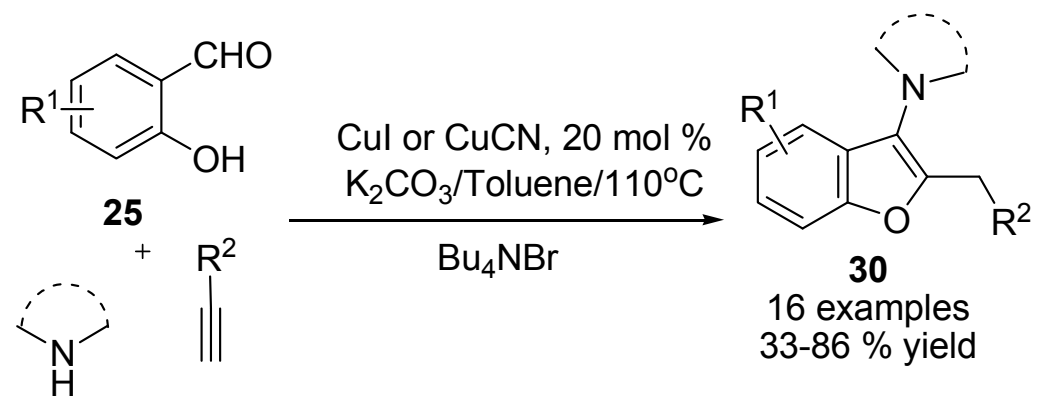

\section{Scheme 14}

$\mathrm{Li}$ and $\mathrm{Yao}^{33}$ reported another interesting three-component reactions of $o$-alkynyl benzaldehydes 31, terminal alkynes and aryl amines for facile synthesis of dihydroisoquinolines 32 with the catalysis of CuOTf and the assistance of Pybox ligand, corresponding heterocyclic products were provided with up to $>99 \%$ yield. The key intermediates were also propargylamines $\mathbf{3 3}$ which underwent intramolecular addition annulation to yield products 32 (Scheme 15). Ts-protected $o$-amino benzaldehydes 34 were similar with salicaldehydes in term of reactivity for many transformations, they also participate in similar three-component transformations with secondary amines and terminal alkynes to yield corresponding $N$-containing heterocycles, dihydroindoles 35. Reactions were performed in the presence of $\mathrm{CuCl} / \mathrm{Cu}(\mathrm{OTf})_{2}$ co-catalysts and DMAP additive, and excellent application scope has been demonstrated (Scheme 16). ${ }^{34}$ 


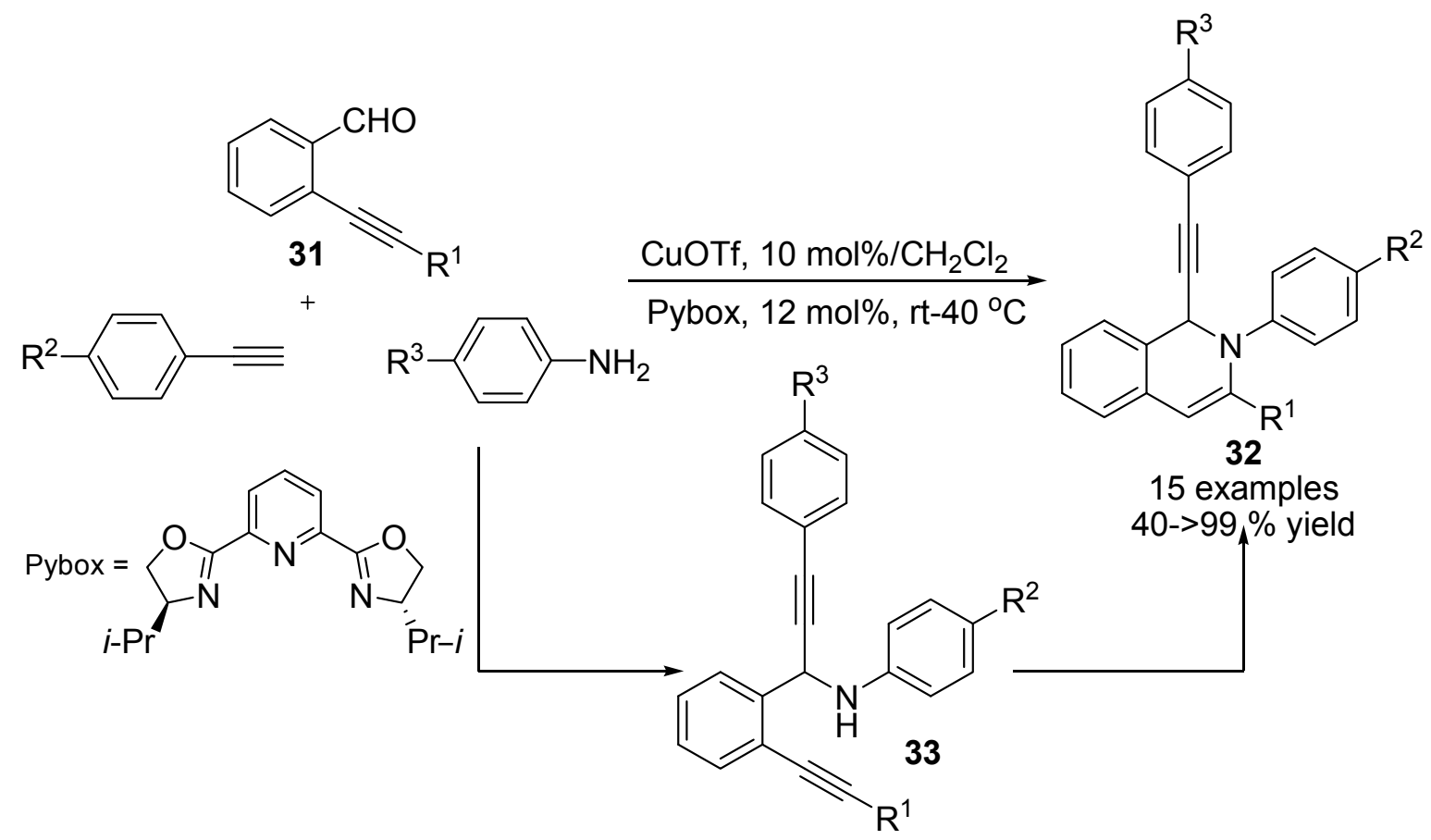

\section{Scheme 15}
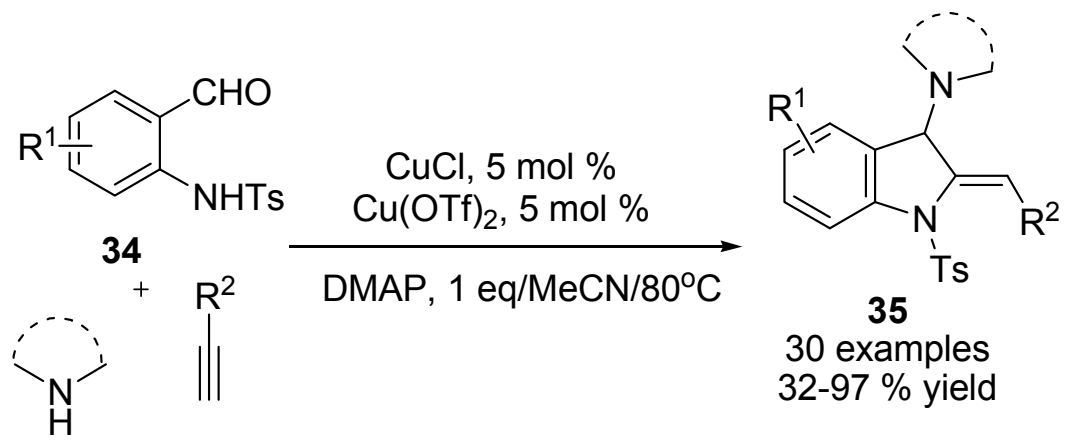

\section{Scheme 16}

Using hydrolyzed formyl carboxylic acid $\mathbf{3 6}, \mathrm{Ji}^{35}$ et al. reported an unprecedented threecomponent selective furanone synthesis, in the presence of secondary amines and terminal alkynes, the three-component reactions proceed under the catalysis of $\mathrm{AuBr}_{3}$ to selectively generate different furanone products $\mathbf{3 7}$ and $\mathbf{3 8}$ at different temperature. The reactions proceed via propargylamines 39 as key intermediates, the intermediates could be activated by gold catalyst to give transition state $\mathbf{4 0}$, and $\mathbf{4 0}$ coupled with electrophiles to provide products $\mathbf{3 7}$ or 39 while releasing catalyst for further recycling process. Besides temperature, the reaction selectivity was also effected by the property of terminal alkynes, aryl alkynes mainly led to the 
productions of 38, while main products obtained from entries using alkyl alkynes were $\mathbf{3 7}$ (Scheme 17).

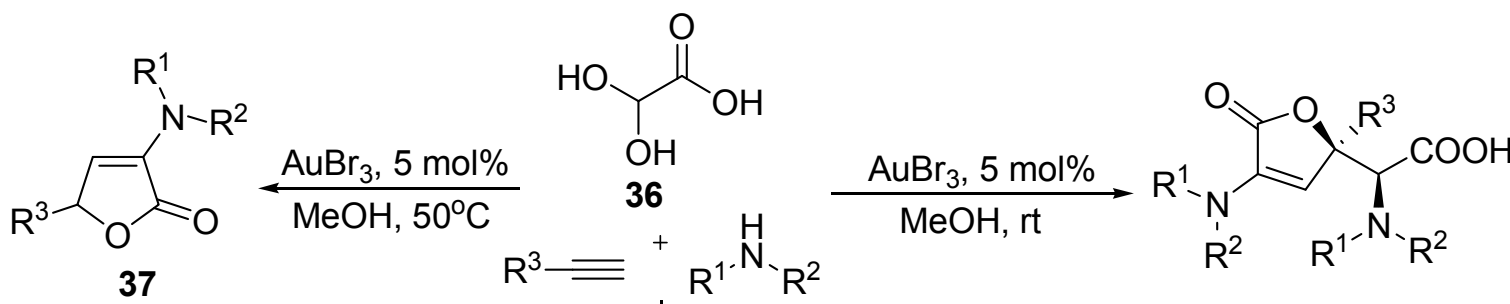

12 examples

$5-78 \%$ yield
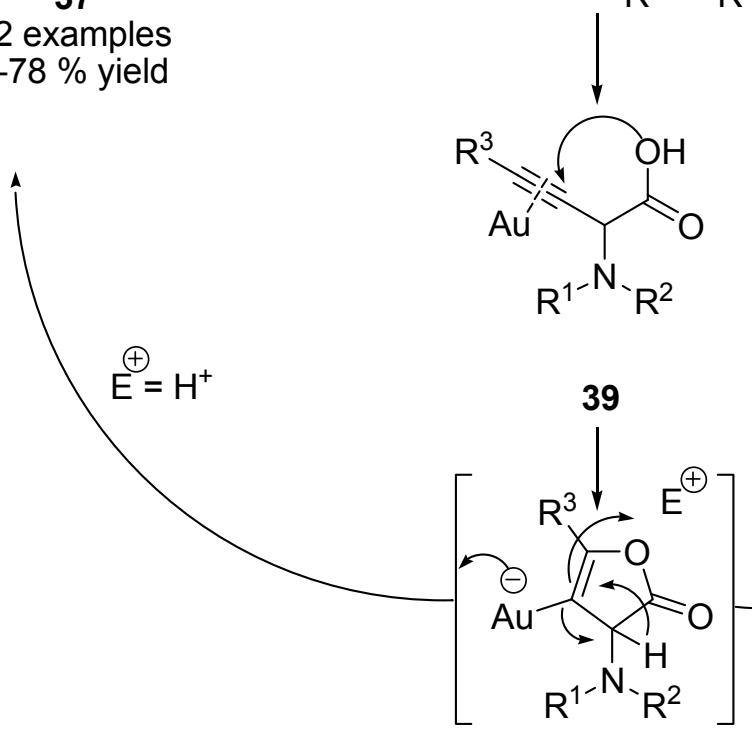

38, $\mathrm{R}^{3}=\mathrm{Ar}$

9 examples

40-76\% yield

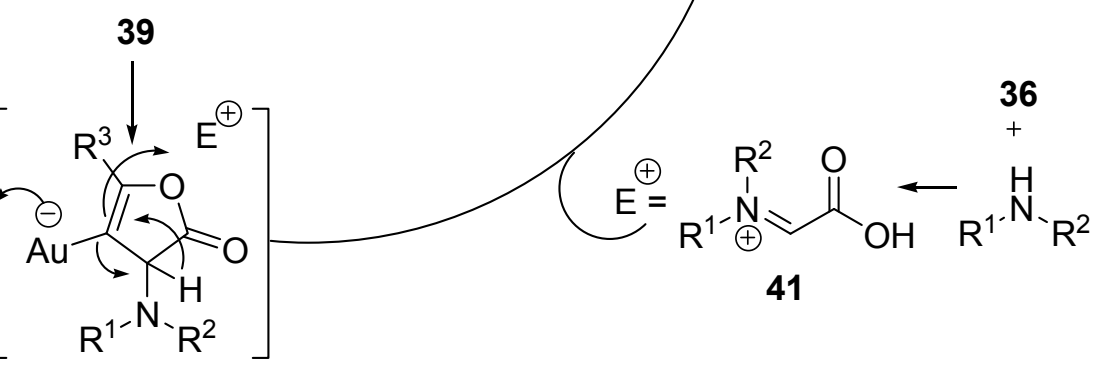

40

\section{Scheme 17}

Another interesting three-component tandem synthesis of heterocycle initiated by $\mathrm{A}^{3}$ coupling has been reported by Li et al in 2012. By employing methyl 2-formylbenzoate $\mathbf{4 2}$ as functional aldehyde component to react with amines and terminal alkynes in the presence of $\mathrm{Cu}(\mathrm{OTf})_{2}$ catalyst. A class of isoindolinones $\mathbf{4 3}$ have been provided via tandem intramolecular amidation cyclization on $\mathrm{A}^{3}$ coupling intermediate 44 . This method afforded products only in moderate to good yields (Scheme 18$)^{36}$ 


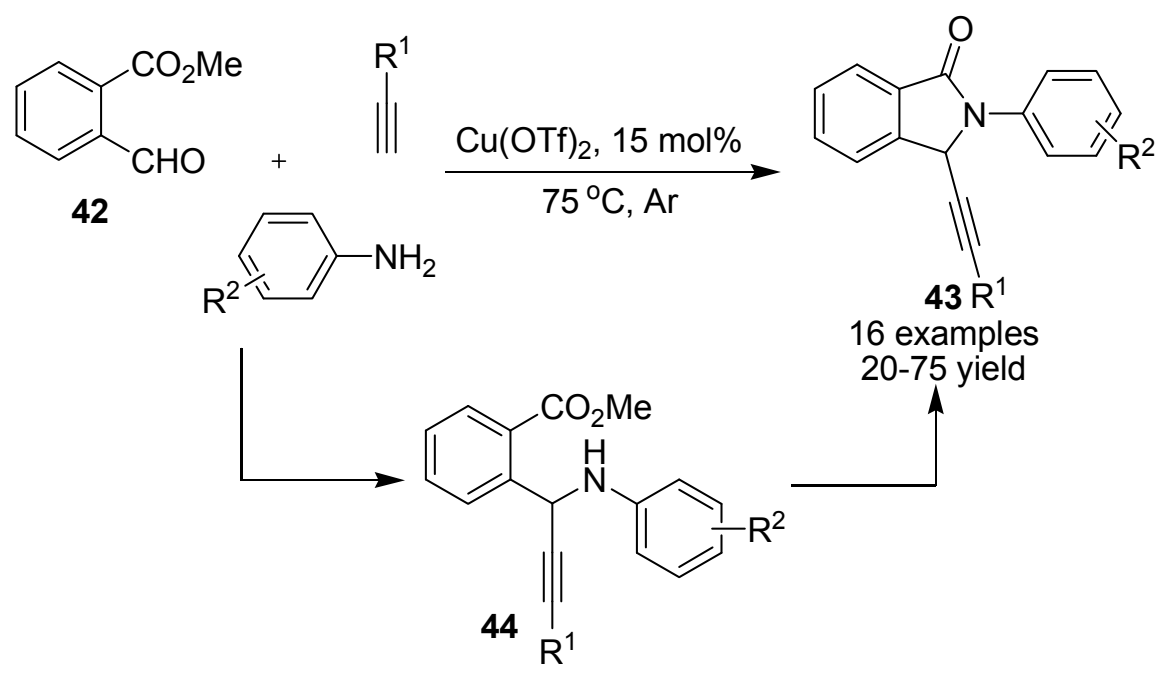

\section{Scheme 18}

Besides the direct tandem cyclization transformation on propargylamines, there was also another kind of $\mathrm{A}^{3}$ coupling-based tandem reactions wherein a fragment in propargylamine intermediates dissociated during transformation. The example was the synthesis of coumarins $\mathbf{4 7}$ via copper-catalyzed reactions of salicylaldehydes and terminal alkynes $\mathbf{4 5}$ in the presence of pyrrolidine. During the reaction process, the intermediates 46 which were generated via tandem $\mathrm{A}^{3}$ coupling and 6-endo-dig cyclization underwent a subsequent hydrolysis transformation to provide 47. It should be noted that products 47 were constructed only by salicylaldehydes and terminal alkynes, this tandem process was not MCRs (Scheme 19). ${ }^{37}$

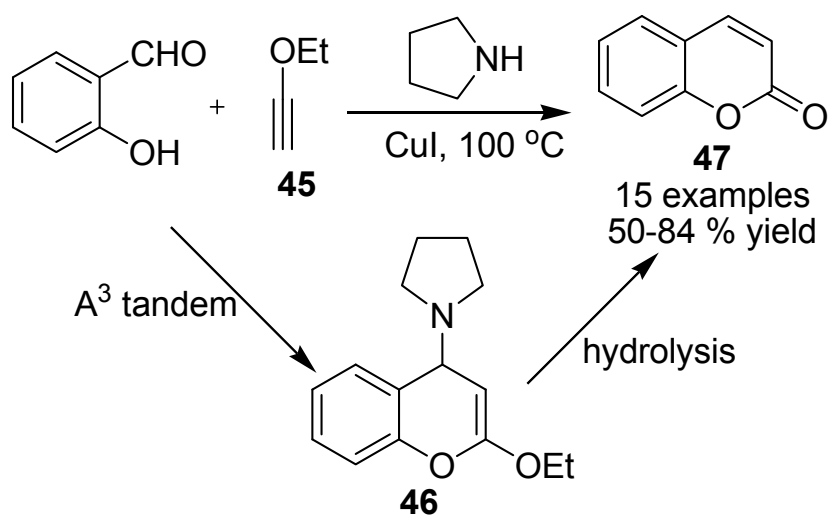

\section{Scheme 19}

\subsection{Reactions based on functional alkyne participated tandem $\mathrm{A}^{3}$ coupling transformation}

Owing to the high reactivity of alkynes, these compounds, especially terminal alkynes are usually unstable, and corresponding alkynes bearing other reactive functional groups are accordingly of less availability compared with amines or aldehydes. Therefore, less examples on 
functional alkynes participated $\mathrm{A}^{3}$ coupling-based tandem reactions are available in literature. A typical example based on functional alkynes was the three-component synthesis of indole derivatives using $o$-aminophenylacetylene 48 , formaldehyde and secondary amines. In the presence of $1 \mathrm{Mol} \% \mathrm{CuBr}$ catalyst, the three-component reactions performed in dioxane at $80{ }^{\circ} \mathrm{C}$ and provided directly indoles 49 . The process of the reactions involved in the $\mathrm{CuBr}$-catalyzed $\mathrm{A}^{3}$ coupling giving intermediates $\mathbf{5 0}$ and further copper-catalyzed intramolecular anuulation (Scheme 20). ${ }^{38}$ The application scope of this three-component synthetic approach has later been extended and more indole products have been synthesized as building blocks for the construction of more complex products. More interestingly, it has been found that aliphatic aldehyde such as butyraldehyde could react with secondary amine and aminophenylacetylenes $\mathbf{4 8}$ to provide 49 with moderate enantioselectivity with the assistance of chiral phosphine ligand (Scheme 21). ${ }^{39}$

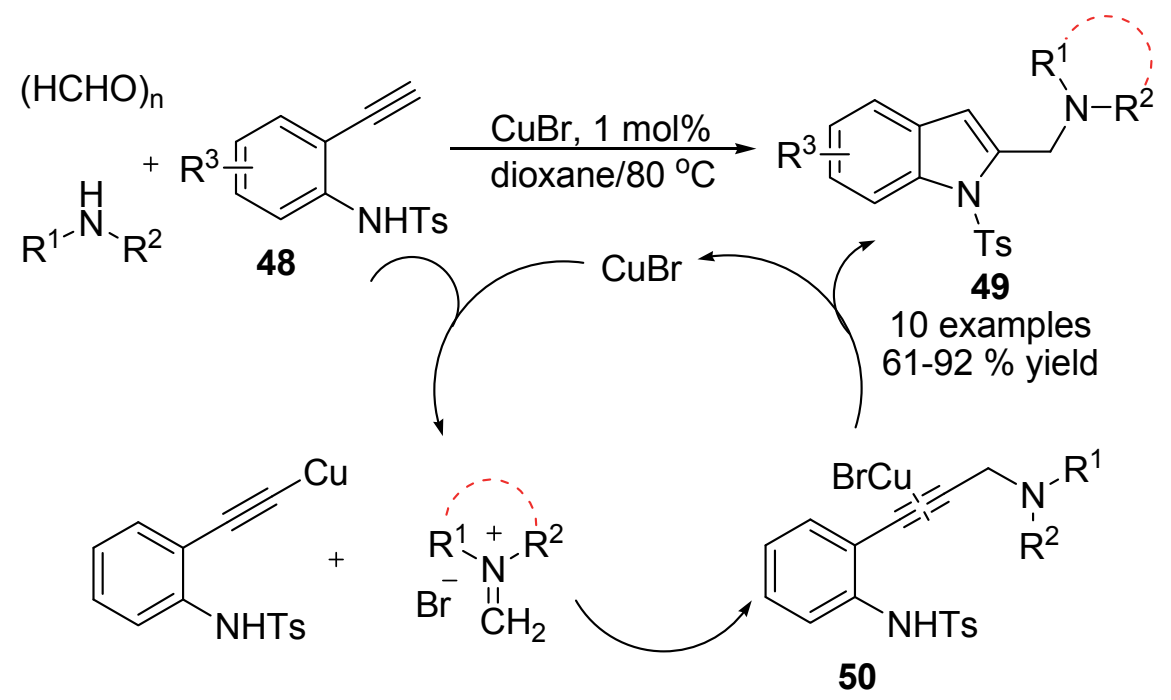

Scheme 20

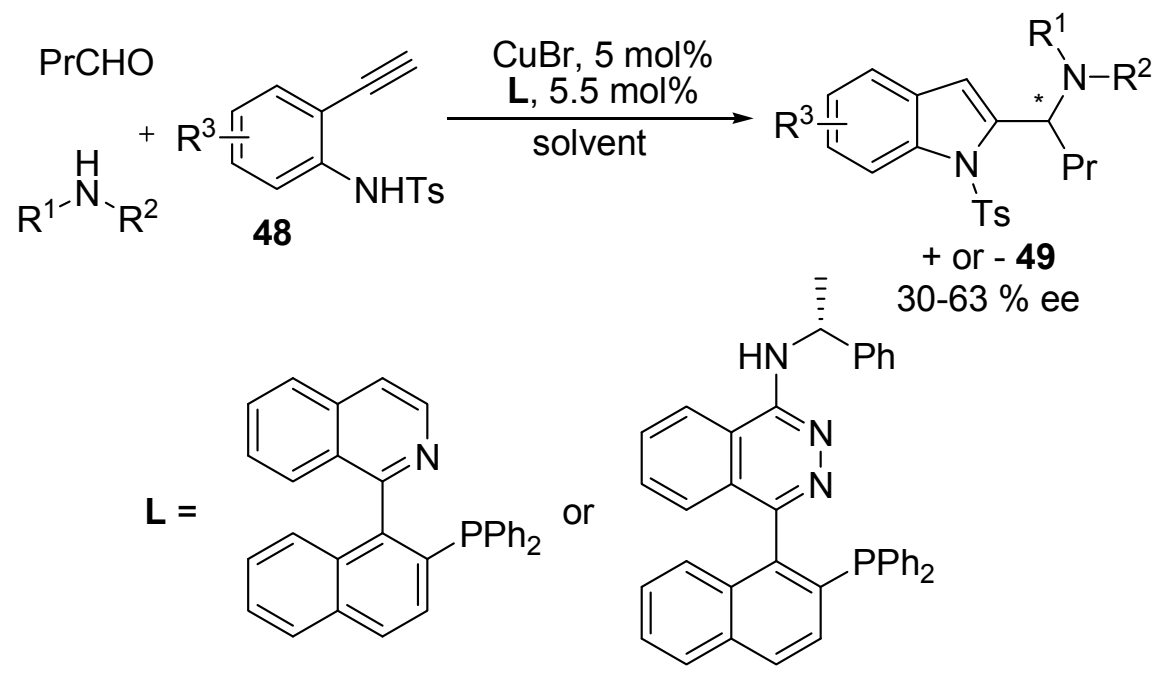

Scheme 21 


\subsection{Reactions of more than three components based on $\mathrm{A}^{\mathbf{3}}$ coupling tandem transformation}

Based on the above introduced contents, it could be easily conclude that those heterocycle synthesis were all designed by making use of a reactant containing two reactive functional groups, these reactions could be classified as intramolecular tandem transformation of propargylamine intermediates, reactions correspond these reactions were the intermolecular transformations of propargylamines, which mean the utilization of additional reactant. The intermolecular tandem transformations were achieved in the fashion of multicomponent assembly by directly employing more than three components based on $\mathrm{A}^{3}$ coupling. Through this strategy some heterocyclic products could be easily accessed. For example, $\mathrm{Li}^{40}$ and co-workers developed an useful method for the synthesis of isoindolines $\mathbf{5 1}$ by employing amine, 2 equiv mole of formaldehyde and 3 equiv mole of terminal alkynes. During the reactions, intermediates 50 which were generated by double $\mathrm{A}^{3}$ coupling reactions underwent $[2+2+2]$ cycloaddition in the presence of additional terminal alkynes to afford target products (Scheme 22).

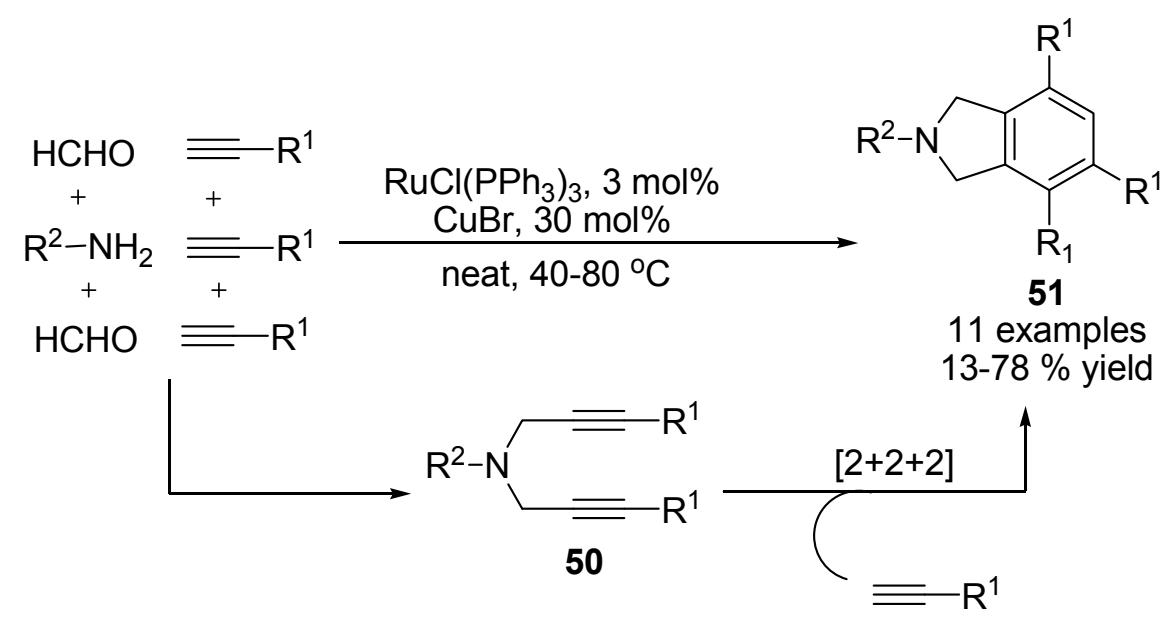

\section{Scheme 22}

In addition, $\mathrm{Li}^{41}$ group also developed the $\mathrm{A}^{3}$ Coupling-based four-component reactions using $\mathrm{A}^{3}$ substrates and carbon dioxide. $\mathrm{CuBr}$ catalyzed the reactions at $70{ }^{\circ} \mathrm{C}$ heating in the atmosphere of $1 \mathrm{~atm} \mathrm{CO}_{2}$ to give oxazolinone products 52. The reactions were achieved through the incorporation of propargylamine intermediates to $\mathrm{CO}_{2}$ as shown in Scheme 23. 


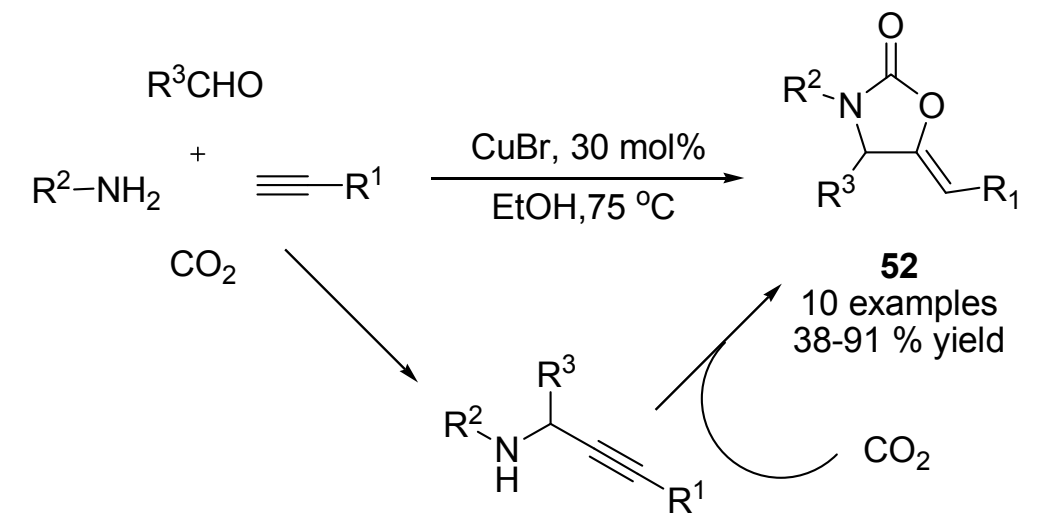<smiles>O=C1O/C(=C\c2ccccc2)C(c2ccccc2)N1Cc1ccccc1</smiles>

$85 \%$<smiles>NC(=O)OCCC1/C(=C/c2ccccc2)OC(=O)N1Cc1ccccc1</smiles>

$38 \%$<smiles>O=C1O/C(=C\c2ccccc2)C(c2ccccc2)N1CCc1ccccc1</smiles><smiles>CCCC1/C(=C/c2ccccc2)OC(=O)N1Cc1ccccc1</smiles>

$78 \%$<smiles>CC(C)CC1C(=Cc2ccccc2)OC(=O)N1Cc1ccccc1</smiles>

$72 \%$<smiles>C=CCN1C(=O)O/C(=C\c2ccccc2)C1c1ccccc1</smiles>

$70 \%$<smiles>COC(=O)c1ccccc1</smiles><smiles>O=C1O/C(=C\c2ccccc2)C([GaH])[C@H]1Cc1ccccc1</smiles><smiles>O=C(O)C=C1OC(=O)N(Cc2ccccc2)C1c1ccccc1</smiles>

$91 \%$

Scheme 23

\section{Conclusions and Outlook}

During the last decade, $\mathrm{A}^{3}$ coupling reaction has evolved to a classical three-component protocol for accessing various propargylamines. Numerous papers have been published on the investigation of this synthetic method and spectacular advances on $\mathrm{A}^{3}$ coupling reactions have been witnessed in terms of green catalyst system, asymmetric catalysis etc. which also promoted this coupling protocol as the most preferred option for propargylamine synthesis. From the perspective of application, the propargylamines possessed broad spectrum of diversity and 
reactivity, and these compounds could serve as main building blocks in the synthesis of many organic small molecules. From the perspective of atom economics, devising tandem reactions based on key transformation of $\mathrm{A}^{3}$ coupling for the synthesis of more complex and structurally diverse heterocyclic products in one-pot represent a promising direction in modern organic synthesis. As introduced in the contents, many elegant results have already been reported on this area. On the other hand, at current state, this kind of tandem reactions were mainly performed by using the second functional group in aldehyde, amine or alkyne to initiate subsequent transformations on propargylamine intermediates, although some reactions using additional components such as carbon dioxide to design tandem synthesis of heterocyclic products have also been reported, this kind of examples are still rather rare. Thus, deeper and broader explore is still demanding since using additional substrates for reactions is theoretically able to provide considerably higher diversity both in reactions and corresponding products. In addition, versions of asymmetric catalysis on traditional $\mathrm{A}^{3}$ coupling have already been accomplished with nice results, while asymmetric catalysis protocols of $\mathrm{A}^{3}$ coupling-based tandem synthesis of heterocycles kept unexplored, more systematic and advanced approaches of asymmetrical catalysis on these tandem reactions are expected in future.

\section{Acknowledgements}

Financial support from NSFC (no. 21202064), a sponsored project from Jiangxi Provincial Department of Education (no. GJJ12211) are gratefully acknowledged.

\section{References}

1. Guermont, J. P. Bull. Soc. Chim. Fr. 1953, 386.

2. Li, C.-J.; Wei, C. Chem. Commun. 2002, 268.

http://dx.doi.org/10.1039/b108851n

3. Wei, C.; Li, C-J. J. Am. Chem. Soc. 2003, 125, 9584.

http://dx.doi.org/10.1021/ja0359299

PMid:12904013

4. Wei, C.; Zhang, L.; Li, C.-J. Synlett 2004, 1472.

5. Li, C.-J. Acc. Chem. Res. 2010, 43, 581.

http://dx.doi.org/10.1021/ar9002587

PMid:20095650

6. Yoo, W.-J.; Zhao, L.; Li, C.-J. Aldrichimica Acta 2011, 44, 43.

7. Zani, L.; Bolm, C. Chem. Commun. 2006, 4263.

http://dx.doi.org/10.1039/b607986p

PMid:17047838 
8. Kouznetsov, V. V.; Méndez, L. Y. V. Synthesis 2008, 491. http://dx.doi.org/10.1055/s-2008-1032148

9. Peshkov, V. A.; Pereshivko, O. P.; Van der Eycken, E. V. Chem. Soc. Rev. 2012, 41, 3790. http://dx.doi.org/10.1039/c2cs15356d

PMid:22422343

10. Huma, H. Z. S.; Halder, R.; Kalra, S. S.; Das, J.; Iqbal, J. Tetrahedron Lett. 2002, 43, 6485. http://dx.doi.org/10.1016/S0040-4039(02)01240-6

11. Xiao, F.; Chen, Y.; Liu, Y.; Wang, J. Tetrahedron 2008, 64, 2755. http://dx.doi.org/10.1016/j.tet.2008.01.046

12. Cao, K.; Zhang, F.-M.; Tu, Y.-Q.; Zhang, X.-T.; Fan, C.-A. Chem. Eur. J. 2009, 15, 6332. http://dx.doi.org/10.1002/chem.200900875

PMid:19472236

13. Zhang, Y.; Li, P.; Wang, L. J. Heterocycl. Chem. 2011, 48, 153. http://dx.doi.org/10.1002/jhet.417

14. Zhang, M.; Wang, T.; Xiong, B.; Yan, F.; Wang, X.; Ding, Y.; Song, Q. Heterocycles 2012, 85,639 . http://dx.doi.org/10.3987/COM-12-12433

15. Yao, C.; Qin, B.; Zhang, H.; Lu, J.; Wang, D.; Tu, S. RSC Adv. 2012, 2, 3759. http://dx.doi.org/10.1039/c2ra20172k

16. Kumar, A.; Rao, V. K. Synlett 2011, 2157. http://dx.doi.org/10.1055/s-0030-1261200

17. Tang, J.; Wang, L.; Mao, D.; Wang, W.; Zhang, L.; Wu, S.; Xie, Y. Tetrahedron 2011, 67, 8465. http://dx.doi.org/10.1016/j.tet.2011.09.004

18. Anvar, S.; Mohammadpoor-Baltork, I.; Tangestaninejad, S.; Moghadam, M.; Mirkhani, V.; Khosropour, A. R.; Kia, R. RSC Adv. 2012, 2, 8713. http://dx.doi.org/10.1039/c2ra20639k

19. Gaddam, V.; Ramesh, S.; Nagarajan, R. Tetrahedron 2010, 66, 4218. http://dx.doi.org/10.1016/j.tet.2010.03.095

20. Chen, X.-L.; Zhang, J.-M.; Shang, W.-L.; Lu, B.-Q.; Jin, J.-A. J. Fluor. Chem. 2012, 133, 139. http://dx.doi.org/10.1016/j.jfluchem.2011.08.005

21. Liu, P.; Pan, Y.-M.; Xu, Y.-L.; Wang, H.-S. Org. Biomol. Chem. 2012, 10, 4696. http://dx.doi.org/10.1039/c2ob25487e PMid:22592555

22. Chernyak, N.; Gevorgyan, V. Angew. Chem. Int. Ed. 2010, 49, 2743. http://dx.doi.org/10.1002/anie.200907291 PMid:20213787 PMCid:PMC3516864

23. Mishra, S.; Ghosh, R. Synthesis 2011, 3463. 
24. Guchhait, S. K.; Chandgude, A. L.; Priyadarshani, G. J. Org. Chem. 2012, 77, 4438.

http://dx.doi.org/10.1021/jo3003024

PMid:22486279

25. Yan, B.; Liu, Y. Org. Lett. 2007, 9, 4323.

http://dx.doi.org/10.1021/o1701886e

PMid:17854200

26. Bai, Y.; Zeng, J.; Ma, J.; Gorityala, B. K.; Liu, X.-W. J. Comb. Chem. 2010, 12, 696. http://dx.doi.org/10.1021/cc100086h

PMid:20831266

27. Patil, S. S.; Patil, S. V.; Bobade, V. D. Synlett 2011, 2379.

28. Mishra, S.; Naskar, B.; Ghosh, R. Tetrahedron Lett. 2012, 53, 5483. http://dx.doi.org/10.1016/j.tetlet.2012.07.113

29. Dighe, S. U.; Hutait, S.; Batra, S. ACS Comb. Sci. 2012, 14, 665. http://dx.doi.org/10.1021/co300123y

PMid:23135420

30. Nguyen, R.-V.; Li, C.-J. Synlett 2008, 1897.

31. Sakai, N.; Uchida, N.; Konakahara, T. Tetrahedron Lett. 2008, 49, 3437. http://dx.doi.org/10.1016/j.tetlet.2008.03.111

32. Li, H.; Liu, J.; Yan, B.; Li, Y. Tetrahedron Lett. 2009, 50, 2353. http://dx.doi.org/10.1016/j.tetlet.2009.02.204

33. Yu, M.; Wang, Y.; Li, C.-J.; Yao, H. Tetrahedron Lett. 2009, 50, 6791. http://dx.doi.org/10.1016/j.tetlet.2009.09.095

34. Chernyak, D.; Chernyak, N.; Gevorgyan, V. Adv. Synth. Catal. 2010, 252, 961. http://dx.doi.org/10.1002/adsc.201000015 PMid:23620715 PMCid:PMC3633492

35. Zhang, Q.; Cheng, M.; Hu, X.; Li, B.-G.; Ji, J.-X. J. Am. Chem. Soc. 2010, 132, 7256. http://dx.doi.org/10.1021/ja101804p

PMid:20455531

36. Sun, L. X.; Zeng, T.; Jiang, D.; Dai, L.-Y.; Li, C.-J. Can. J. Chem. 2012, 90, 92. http://dx.doi.org/10.1139/v11-108

37. Reddy, M. S.; Thirupathi, N.; Haribabu, M. Beilstein J. Org. Chem. 2013, 9, 180. http://dx.doi.org/10.3762/bjoc.9.21 PMid:23400373 PMCid:PMC3566765

38. Ohno, H.; Ohta, Y.; Oishi, S.; Fujii, N. Angew. Chem. Int. Ed. 2007, 46, 2295. http://dx.doi.org/10.1002/anie.200604342

PMid:17300118

39. Ohta, Y.; Chiba, H.; Oishi, S.; Fujii, N.; Ohno, H. J. Org. Chem. 2009, 74, 7052. http://dx.doi.org/10.1021/jo901328q

PMid:19673483 
40. Bonfield, E. R; Li, C.-J. Adv. Synth. Catal. 2008, 350, 370.

http://dx.doi.org/10.1002/adsc.200700500

41. Yoo, W.-J.; Li, C.-J. Adv. Synth. Catal. 2008, 350, 1503.

http://dx.doi.org/10.1002/adsc.200800232

\section{Author's Biography}

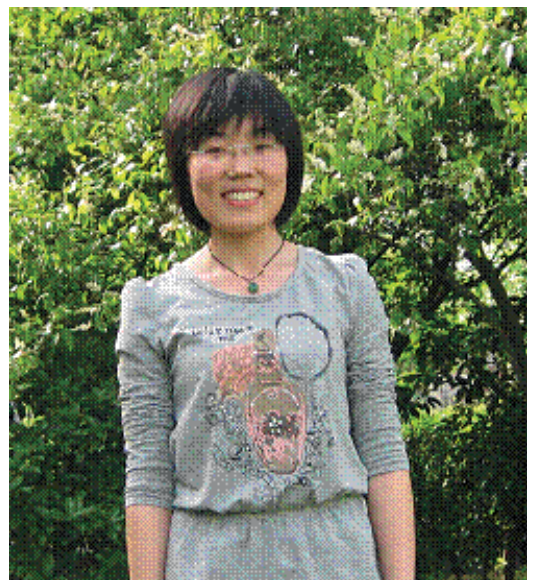

Dr. Yunyun Liu was born in 1983 in Shandong Province, China. She obtained her Bachelor Degree in Qufu Normal University in 2005. She then moved to Zhejiang University to continue her graduate study in the Department of Chemistry. Under the supervision of Professor Weiliang Bao, she worked on the field of copper-catalyzed Ullmann coupling reaction and related tandem reactions for her doctorate study. She obtained her doctorate degree in 2010 and presently she is an assistant professor in Jiangxi Normal University. She is currently interested in the research of metal-catalyzed organic synthesis and the development of new cascade organic reactions. 